\title{
Hubungan Pemberian ASI Ekslusif Dengan Tumbuhan Kembang Anak Usia Todler di Wilayah Kerja Puskesmas Pardamean Pematang Siantar Tahun 2018
}

\author{
${ }^{(1)}$ Ria Lusi Utami, ${ }^{(2)}$ Maswan Daulay \\ Universitas Efarina Pematang Siantar ${ }^{(1)}(2)$ \\ $\underline{\text { Ria.lusi91@gmail.com }}^{(1)}$, maswandaulay@gmail.com ${ }^{(2),}$
}

\begin{abstract}
ABSTRAK
Masa penting dalam pertumbuhan dan perkembangan anak adalah usia balita. Pada saat ini ada pertumbuhan dasar yang akan mempengaruhi dan menentukan perkembangan anak selanjutnya. Selama periode ini, stimulasi atau stimulasi diperlukan untuk mengembangkan potensinya. Perkembangan anak akan optimal jika interaksi dicari sesuai dengan kebutuhan anak di berbagai tahap perkembangan. Tujuan dari penelitian ini adalah untuk mengetahui hubungan pemberian ASI eksklusif dengan pertumbuhan dan perkembangan usia balita. Desain penelitian ini adalah case control. Populasi kasus dalam penelitian ini adalah populasi cas adalah anak-anak yang menerima menyusui eksklusif dari Juli hingga Agustus 201 sebanyak 22 anak yang bekerja adalah dari Puskesmas Pardamean Pematangsiantar. Teknik pengambilan sampel dalam penelitian ini adalah menggunakan purposive sampling dengan kriteria inklusi dan eksklusi. Data yang diperoleh dalam penelitian ini dianalisis menggunakan rumus statistik uji Chi-square dengan tingkat signifikansi $(\mathrm{a}=0,05)$. Hasil penelitian ini menunjukkan tidak ada hubungan antara pemberian ASI eksklusif dan pertumbuhan usia balita $(\mathrm{p}=0,053)$. Demikian juga tidak ada hubungan menyusui eksklusif dengan perkembangan anak $(\mathrm{p}=0,215)$. Meskipun tidak ada hubungan yang signifikan yang ditemukan dalam penelitian ini, tampak bahwa kecenderungan anak-anak yang memiliki pertumbuhan dan perkembangan abnormal berasal dari kelompok eksklusif yang tidak menyusui. Perlu disosialisasikan pentingnya pemberian ASI eksklusif untuk perkembangan anak.
\end{abstract}

Kata Kunci : ASI Eksklusif, Pertumbuhan dan Perkembangan, Anak Usia Balita

\begin{abstract}
An important period in the childs growth and development is toddler age. At this time there is a basic growth that will influence and determine the development of the next child. During this period, stimulation or stimulation is needed to develop its potential. Child development will be optimal if interactions are sought according to the needs of children at various stages of development. The purpose of the study was to determine the relationship of exclusive breastfeeding to toddler age growth and development. The design of this research is case control. The case population in this study was the cas population were are children who received eclusive breastfeeding from July to August 201 as many as 22 children in the working are of Pardamean Health Center Pematangsiantar. The sampling technique in this study is to use purposive sampling with inclusion and exclusion criteria. The data obtained in this study were analyzed using the Chi-square test statistic formula with significance level $(a=0,05)$. The results of this study showed no relationship between exclusive breastfeeding and toddler age growth $(\mathrm{p}=0.053)$. Likewise there is no exclusive breastfeeding relationship with child development $(p=0.215)$. Altough no significant relationship was found in this study, it appeared that the tendency of children who had abnormal growth and development came from the exclusive non-breastfeeding group. It is necessary to socialize the importance of exclusive breastfeeding of child development.
\end{abstract}

Keywords : Exclusive ASI, Growth and Development, Toddler Age Children 
Lusi Utami R, Daulay M : Hubungan Pemberian ASI Ekslusif Dengan Tumbuh Kembang Anak Usia Todler di Wilayah Kerja Puskesmas Pardamean Pematang Siantar

\section{PENDAHULUAN}

\section{Latar Belakang}

Pertumbuhan terjadi pada seseorang meliputi perubahan fisik, berpikir, berperasaan, bertingkah laku dan lain-lain. Sedangkan perkembangan yang dialami seorang anak merupakan rangkaian perubahan secara teratur dari satu tahap perkembanagan ke tahap perkembangan berikutnya dan berlaku secara umum, missal : anak berdiri dengan satu kaki, berjingkat (berjinjit), berjalan, menaiki tangga, berlari dan seterusnya. Untuk mencapai perkembangan tumbuh kembang anak yang optimal perlu diperhatikan beberapa aspek perkembangan, yakni sensoris, motorik, komunikasi bahasa dan bicara, kognitif, kreatifitas seni, urus diri, emosi social, kerja sama dan leadership, serta moral dan spiritual. Dimana perkembangan itu berkaitan dengan perkembangan otak anak juga. Jika melihat dari perkembangan otak, otak terbagi menjadi 2 sisi, yakni otak kiri (hard skill $10 \%$ ) specifi competenciens berhubngan dengan logika, berhitung, rasional, dan merencanakan. Otak kanan (soft skill 90\%) basic competenciens sensitiveness, self controlling, vision, communication, risk taking dan continual learning. Kemudian dalam tahap perkembangan tumbuh kembang anak, anak berusia 12 bulan seharusnya sudah bisa untuk berjalan di tuntun, makan dengan sendok, dipanggil dating, dan bicara lebih dari 8 kata. Usia 18 bulan sudah bisa untuk naik tangga dibantu, susun balok enam dan mengikuti mimik (Hurloc, 2008). Periode penting pada tumbuh kembang anak yaitu pada usia toddler. Pada masa ini terjadi pertumbuhan dasar yang akan mempengaruhi dan menentukan perkembangan anak selanjutnya. Pada masa periode ini, diperlukan rangsangan atau stimulasi yang berguna agar potensinya berkembang. Perkembangan anak akan optimal bila interaksi diusahakan sesuai dengan kebutuhan anak pada berbagai tahap perkembangannya (Soetjaningsih, 2008). Anak usia 1-3 tahun cenderung gerakannya memakai otat-otot besar, bergerak dengan banyak komponen tubuh dan dapat merangsang oksigegasi otak. Dan untuk mengetahui anak sudah siap jalan atau belum dapat dilihat dari reflex jinjit (plantar reflex) yang mulai hilang, atau sudah dapat melakukan koordinasi komplek (Hurlock, 2008).

\section{Perumusan Masalah}

Pertumbuhan dan perkembangan anak usia toddler sebagian besar ditentukan oleh jumlah ASI yang diperoleh, termasuk energy dan zat gizi lainnya yang terkandung di dalam ASI tersebut. ASI tanpa bahan makanan lain dapat mencukupi kebutuhan pertumbuhan usia sekitar enam bulan. Pemberian ASI tanpa pemberian makanan lain selama enam bulan tersebut dengan menyusui secara ekslusif. ASI memiliki berbagai manfaat yang baik untuk pertumbuhan adan perkembangan anak juga dapat menurunkan risiko terjadinya penyakit akut dan kronik (Pertiwi, 2012). Dimana Air Susu Ibu ( ASI ) merupakan makanan terbaik yang sangat dibutuhkan oleh anak untuk tubuh dan kembang. Untuk mencapai pertumbuhan anak yang optimal maka ASI hendaknya diberikan secara ekslusif yaitu pemberian ASI tanpa makanan atau cairan lain sampai 6 bulan. Usia 0-24 bulan merupakan masa pertumbuhan dan perkembangan yang pesat, sehingga kerap diistilahkan sebagai periode emas sekaligus periode kritis. Periode emas dapat diwujudkan apabila masa itu anak memperoleh asupan gizi yang sesuai untuk tumbuh kembang optimal. Sebaliknya apabila anak pada masa ini tidak memperoleh makanan sesuai kebutuhan gizinya, maka periode emas akan berubah menjadi periode kritis yang akan mengganggu tumbuh kembang anak, baik pada saat ini maupun masa selanjutnya (Depkes RI, 2010). Berdasarkan profil kesehatan Provinsi Sumatera Utara 2016, jumlah anak sebanyak 163.595, sedangkan jumlah anak yang diberi ASI Eksklusif hanya 97,837 atau hanya 59,80\% saja (Dinas Kesehatan Provinsi Sumatera Utara, Makassar 2016). Dari data yang diperoleh di wilayah kerja Puskesmas Pardamean Pematangsiantar jumlah ibu yanga mempunyai anak yang 
Lusi Utami R, Daulay M : Hubungan Pemberian ASI Ekslusif Dengan Tumbuh Kembang Anak Usia Todler di Wilayah Kerja Puskesmas Pardamean Pematang Siantar

berkunjung pada bulan Mei-Juni 2018 adalah sebanyak 60 orang yang memberkan ASI eksklusif adalah sebanyak 22 orang sedangkan yang tidak memberkan ASI eksklusif sebanyak 38 orang, oleh karena itu perlu kita pikirkan untuk tumbuh kembangnya kedepan agar anak dari setiap ibu tetap mendapatkan ASI eksklusif. Dengan mengetahui begitu pentingnya pemberian ASI eksklusif pada anak usia Todler untuk derajat kesehatan yang baik dan pertumbuhan serta perkembangan yang optimal, sedangkan penerapan ASI eksklusif masih buruk di Indonesia, termasuk Puskesmas Pardamean Pematangsiantar masih sangat rendah, maka peneliti mencoba untuk meneliti permasalahan ini untuk mengetahui Hibungan Pemberian ASI Eksklusif Terhadap Tumbuh Kembang Anak usia Todler di Wilayah Kerja Puskesmas Pardamean Pematangsiantar.

\section{Tujuan Penelitian}

Agar masyarakat memahami pentingnya pemahaman berdasarkan hasil Riset Kesehatan Dasar (Riskesdas) 2010 di Indonesia menunjukan pemberian ASI baeru mencapai 15,3\% dan pemberian susu formula meningkat tiga kali lipat dari 10,3\% menjadi 32,5\%. Kesadaran masyarakat dalam mendorong peningkatan pemberian ASI masih relative rendah, termasuk didalamnya kurangnya pengetahuan ibu hamil, keluarga dan masyarakat akan pentingnya ASI, kurangnya pelayanan konseling laktasi dan dukungan dari petugas keseshatan, kondisi yang kurang memadai bagi para ibu yang bekerja (cuti melahirkan yang terlalu singkat, tidak adanya ruang di tempat kerja untuk menyusui atau memompa ASI). Dan pemasaran agresif oleh perusahaan-perusahaan susu formula yang menghubungani para ibu.

\section{METODE PENELITIAN}

Penelitian ini menggunakan desain observasional dengan pendekatan case control. Desain studi ini di fokuskan untuk mengetahui hubungan pemberian ASI Eksklusif terhadap tumbuh kembang anak usia Todler (Nursalam, 2002). Penelitian dilakukan di wilayah kerja wilayah Puskesmas Pardamean Pematangsiantar. Waktu penelitian dilaksanakan sejak bulan JuliAgustus 2018. Populasi dalam penelitian ini adalah anak yang mendapatkan ASI eksklusif sejak Januari-Mei 2013 sebanyak 22 anak. Tehnik pengambilan sampel yang digunakan adalah Purposive Sampling. Metode Instrumen penelitian yang digunakan dalam penelitian ini adalah kuesioner. Tehnik Pengolahan Data yaitu seleksi, editing, koding dan tabulasi. Analisis data yaitu analisis univariat dan bivariat.

\section{HASIL DAN PEMBAHASAN}

\section{Analisis Univariat}

Karakteristik Sampel Berdasarkan Umur dan Jenis Kelamin

Tabel 1 Karakteristik Sampel Berdasarkan Umur dan Jenis Kelamin Di Wilayah Kerja Puskesmas Pardamean Pematangsiantar Tahun 2018

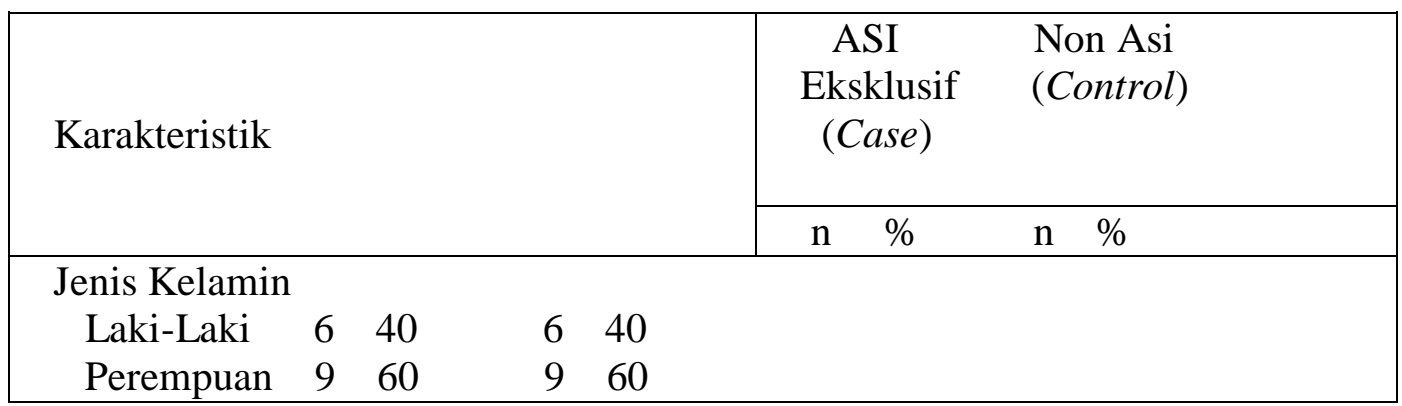


Lusi Utami R, Daulay M : Hubungan Pemberian ASI Ekslusif Dengan Tumbuh Kembang Anak Usia Todler di Wilayah Kerja Puskesmas Pardamean Pematang Siantar

\begin{tabular}{|lrrrrr|}
\hline Jumlah & 15 & 100 & 15 & 100 \\
& & & & \\
\hline Umur & & & & \\
12-24 bulan & 5 & 33,3 & 8 & 53,3 \\
25-36 bulan & 10 & 66,7 & 7 & 46,7 \\
\hline Jumlah & 15 & 100 & 15 & 100 \\
\hline
\end{tabular}

Berdasarkan tabel 1, menunjukkan bahwa daftar distribusi anak dengan jenis kelamin laki-laki pada kelompok kasus dan kontrol berjumlah 6 anak (40\%) dan 9 anak $(60 \%)$ berjenis kelamin perempuan. Sementara umur 12-24 bulan pada kelompok kasus berjumlah 5 anak $(33,3 \%)$, dan umur 25-36 bulan berjumlah 10 anak $(66,7 \%)$ dan pada kelompok kontrol umur 12-24 bulan berjumlah 8 anak $(53,3 \%)$, dan umur 25-36 bulan berjumlah 7 anak $(46,7 \%)$.

a. Karakteristik Sampel Berdasarkan Pertumbuhan Anak Usia Todler

Tabel 2 Karakteristik Sampel Berdasarkan Pertumbuhan Anak Usia Todler Di Wilayah Kerja Puskesmas Pardamean Pematangsiantar Tahun 2018

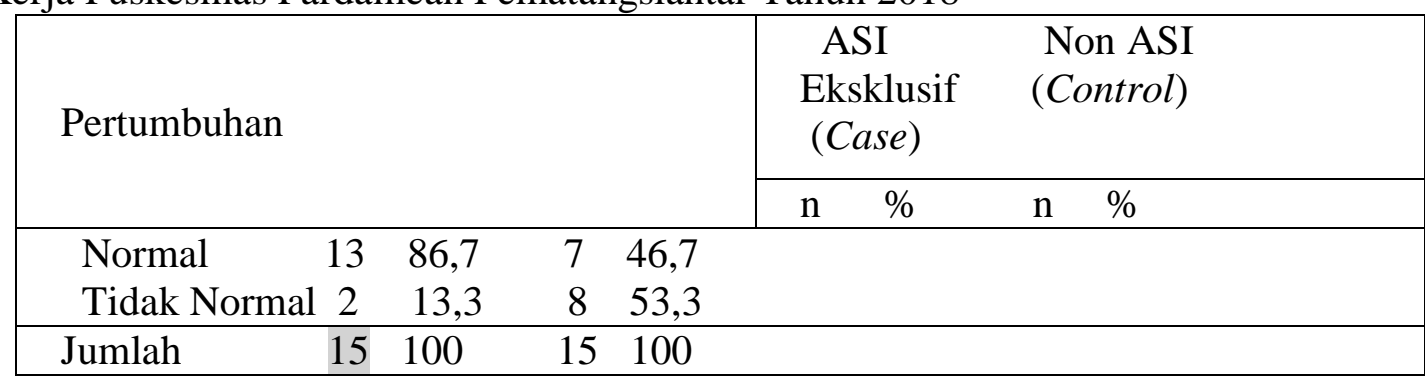

Tabel 2, menunjukkan bahwa distribusi pertumbuhan anak pada kelompok kasus dengan pertumbuhan normal yaitu berjumlah 13 anak $(86,7 \%)$ dan anak dengan pertumbuhan tidak normal berjumlah 2 anak (13,3\%). Sedangkan pada kelompok kontrol dengan pertumbuhan normal yaitu berjumlah 7 anak $(46,7 \%)$ dan anak dengan pertumbuhan tidak normal berjumlah 8 anak $(53,3 \%)$.

b. Karakteristik Sampel Berdasarkan Perkembangan Anak Usia Todler

Tabel 3 Karakteristik Sampel Berdasarkan Perkembangan Anak Usia Todler Di Wilayah Kerja Puskesmas Pardamean Pematangsiantar Tahun 2018

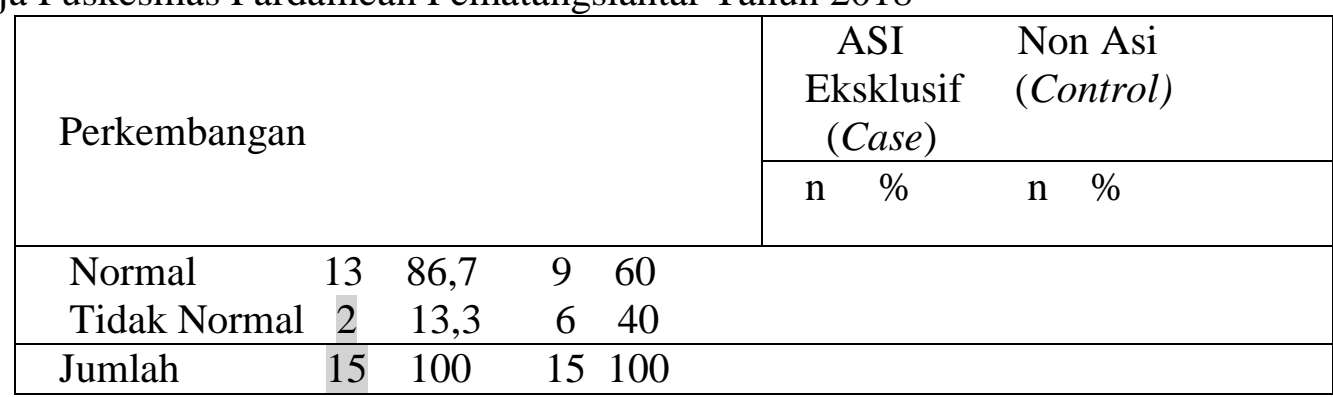

Tabel 3, menunjukkan distribusi perkembangan anak pada kelompok kasus dengan perkembangan normal yaitu berjumlah 13 anak $(86,7 \%)$ dan anak dengan perkembangan tidak normal berjumlah 2 anak (13,3\%). Sedangkan pada kelompok kontrol dengan perkembangan normal yaitu berjumlah 9 anak (60\%) dan anak dengan perkembangan tidak normal berjumlah 6 anak (40\%). 
Lusi Utami R, Daulay M : Hubungan Pemberian ASI Ekslusif Dengan Tumbuh Kembang Anak Usia Todler di Wilayah Kerja Puskesmas Pardamean Pematang Siantar

\section{Analisis Bivariat}

a. Hubungan Pemberian ASI Eksklusif Terhadap Pertumbuhan

Tabel 4 Analisis Hubungan ASI Eksklusif Terhadap Pertumbuhan Anak Usia Todler Di Wilayah Kerja Puskesmas Pardamean Pematangsiantar

\begin{tabular}{|c|c|c|c|c|}
\hline \multirow{3}{*}{ Pertumbuhan } & & \multicolumn{3}{|c|}{ Pemberian } \\
\hline & & $\begin{array}{c}\text { ASI } \\
\text { Eksklusif } \\
\text { (Case) }\end{array}$ & $\begin{array}{l}\text { Non ASI } \\
\text { (Control) }\end{array}$ & $\mathrm{P}$ \\
\hline & & $\mathrm{n} \quad \%$ & $\%$ & \\
\hline $\begin{array}{lll}\text { Normal } & 13 & 86,7\end{array}$ & $7 \quad 46,7$ & \multirow[t]{2}{*}{0.053} & & \\
\hline Tidak Normal $2 \quad 13,3$ & 853,3 & & & \\
\hline $\begin{array}{lll}\text { Total } & 15 & 100\end{array}$ & 15100 & & & \\
\hline
\end{tabular}

Table 4, menunjukkan bahwa dari kelompok anak dengan pemberian ASI eksklusif (case) jumlaha anak yang mengalami pertumbuhan normal yaitu 13 anak $(86,7 \%)$ dan yang mengalami pertumbuhan tidak normal sebanyak 2 anak (13,3\%). Sedangkan kelompok anak yang tidak diberkan ASI (control) yang mengalami pertumbuhan normal yaitu 7 anak $(46,7 \%)$ dan yang mengalami pertumbuhan tidak normal sebanyak 8 anak $(53,3 \%)$. Hasil Uji Chi square diperoleh nilai sig X" hitung $(\mathrm{p}=0,053)>(\mathrm{a}=0,05)$, maka Ho diterima berarti tidak ada hubungan pemberian ASI Eksklusif terhadap pertumbuhan anak. Namun, terdapat kecenderungan pertumbuhan tidak normal berasal dari anak yang non ASI.

b. Hubungan Pemberian ASI Eksklusif Terhadap Perkembangan

Tabel 5 Analisis Hubungan ASI Eksklusif Terhadap Perkembangan Anak Usia Todler Di wilayah Kerja Puskesmas Pardamean Pematangsiantar.

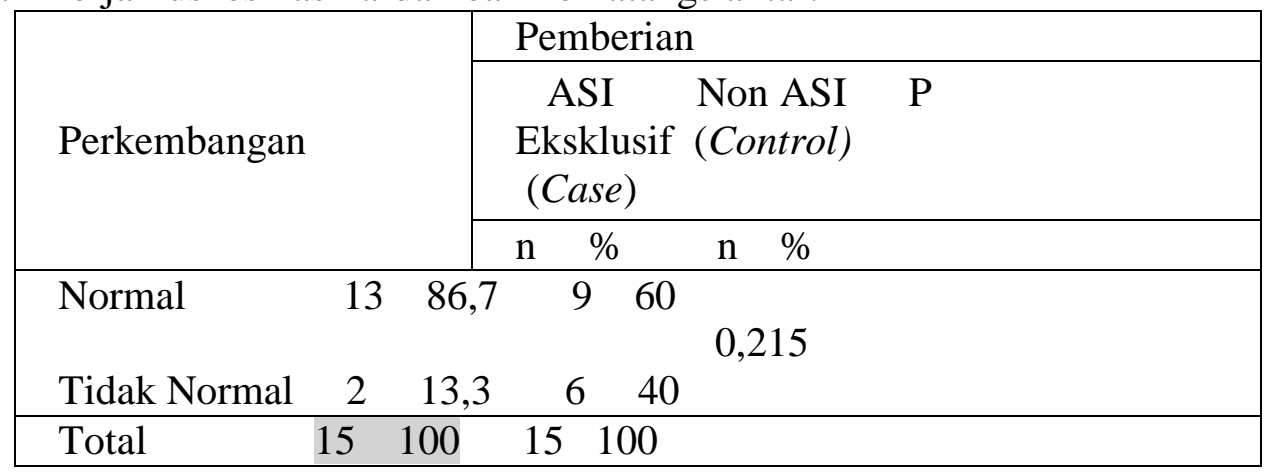

Tabel 5, menunjukkan bahwa anak dengan ASI Eksklusif (case) memiliki jumlah anak dengan perkembangan normal yaitu 13 anak $(86,7 \%)$ dan anak dengan perkembangan tidak normal yaitu 2 anak (13,3\%). Sedangkan anak dengan Non ASI (control) yang memiliki perkembangan normal yairu 9 anak (60\%) dan anak yang memliki perkembangan tidak normal berjumlah 6 anak (40\%). Hasil Uji fisher diperoleh nilai fisher exact's test yaitu $(\mathrm{p}=0,25)>(\mathrm{a}=0,05)$, maka Ho diterima sehingga tidak ada hubungan pemberian ASI Eksklusif terhadap perkembangan anak. Namun dari tabel silang tampak kecenderungan yang memiliki perkembangan tidak normal, mayoritas berasal dari kelompok non ASI 
Lusi Utami R, Daulay M : Hubungan Pemberian ASI Ekslusif Dengan Tumbuh Kembang Anak Usia Todler di Wilayah Kerja Puskesmas Pardamean Pematang Siantar

\section{KESIMPULAN}

1. Tidak ada hubungan antara pertumbuhan anak usia Todler (1-3 tahun) yang mendapatkan ASI Eksklusif di wilayah kerja Pardamean Pematangsiantar dengan nilai $(\mathrm{p}=0,053)>(\mathrm{a}=0,05)$ dan nilai OR sebesar 7,429. Hal ini berarti anak yang tidak diberi ASI Eksklusif memiliki kemungkinan 7,429 kali lebih besar mengalami pertumbuhan yang tidak normal.

2. Tidak ada hubungan ASI Eksklusif dengan perkembangan anak usia Todler di wilayah kerja Puskesmas Pardamean Pematangsiantar dengan nilai $(\mathrm{p}=0,215)>(\mathrm{a}=0,05)$ dan nilai OR sebesar 4,333. Hal ini berarti anak yang tidak diberi ASI Eksklusif memiliki kemungkinan 4,3 kali lebih besar mengalami perkembangan yang tidak normal.

\section{DAFTAR PUSTAKA}

Afrianto, Ahmad. 2010. Artikel Keperawatan Keluarga Dengan Kurang Gizi. From:www.Petanikeren.wordpres.com. Diakses pada 10 Juli 2018. Arikunto, Suharsini. 2006. Prosedur Penelitian Suatu Pendekatan Praktek. Jakarta: PT Rineka Cipta.

Basuki, Dian N. 2009. “Mengapa Menyusui Perlu Dilindungi”.FKUI http://www.gizi.net Diakses 5 Mei 2018.

Danuatmaja, Bonny. 2006. 40 Hari Pasca Persalinan. Jakarta : Puspa Swara.

Departemen Kesehatan RI. 2007. "Hanya 3,7\% Bayi Memperoleh ASF”.

http://www.dpkes.go.id Diakses 9 Mei 2018

Depkes RI. 2010. Pedoman Umum Pemberian Makanan Pendamping Air Susu Ibu (MPASI) Lokal. Jakarta.

Hadju, Veny. 2001. Meningkatkan Status Gizi Anak Balita Melalui Perbaikan Kualitas MPASI Lokal. LP Unhas. Makasar.

Hurlock, E. B. 2008. Psikologi Perkembangan. Edisi 5. Jakarta : Erlangga.

Indiarti. 2009. ASI Susu Formula \& Makanan Bayi. Yogyakarta : Elmatera Publishing.

Minarno, Eko, Budi, Hariani, Liliek. 2008. Gizi dan Kesehatan. UIN Malang Press : Malang.

Murniati. 2010. Faktor-faktor yang Berhubungan dengan Pemberian ASI Eksklusif Bayi Umur 6-12 Bulan di Puskesmas Samata. Skripsi FIK UIN Makassar.

Naim, K. (2001). "Hubungan Pemberian ASI Eksklusif Terhadap Kejadian Pneumonia Pada Anak Umur 4-34 Bulan di Kabupaten Indramayu”. Tesis. Universitas Indonesia Depok.

http://journal.ui.ac.id/index.php/mgmi/article/download/427/369.pdf Diakses 11 Juni 2018.

Novita, D. 2008 . Hubungan karakteristik ibu, faktor pelayanan kesehatan, Immediate breastfeeding dan pemberian kolostrum dengan pemberian ASI eksklusif di wilayah kerja Puskesmas Pancoran Mas Depok tahun 2008. Skripsi : Universitas Indonesia.

Nugroho, Taufan. 2011. ASI dan tumor Payudara. Yogyakarta:Nuha Medika.

Nursalam. 2003. Konsep Dan Penerapan Metodologi Penelitian ilmu Keperawatan. Jakarta : Salemba Medika.

Pertiwi, Putri. 2012. Gambaran Faktor-Faktor Yang Mempengaruhi Pemberian ASI Eksklusif Di Kelurahan Kinciran Indah Tangerang. Skripsi FIK UI.http://fk.Ub.ac.id/artikel/id/filedownload/gizi/PUTRI\%20M\%2PERTIWI.pdf Diakses 5 Juni 2018.

Prasetyono, Dwi S. 2009. Buku pintar aSI Eksklusif. Jogjakarta : Diva press.

Primayanti, S. 2009. Hubungan karakteristik ibu, dukungan keluarga dan

pendidikan kesehatan dengan perilaku pemberian ASI dan MP-ASI pada bayo usia 0-12 bulan dalam konteks keperawatan komunitas di Desa Warn Jawa Kecamatan Parting 
Lusi Utami R, Daulay M : Hubungan Pemberian ASI Ekslusif Dengan Tumbuh Kembang Anak Usia Todler di Wilayah Kerja Puskesmas Pardamean Pematang Siantar

Kabupaten Bogor. Tesis. Universitas Indonesia.http://library.u.ac.id/download/fkm/fkm-siska.pdf Diakses 5 Juni 2018

Ramaiah, Savitri. 2007. Manfaat Asi dan Menyusui. PT. Buana Ilmu populer: Jakarta.

Rodiah. 2012. "Hubungan Pwmberian ASI Eksklusif Dengan Tumbuh Kembang Pada Anak Usia 3-6 Bulan di Puskesmas Karanganyar".

http://ejournal.dinkesjatengprov.go.id/document/2012/ARTIKEL/HUBUNGAN\%20PEM BERIAN\%20ASI\%2EKSKLUSIF\%20

DENGAN\%20TUMBUH\%20KEMBANG\%20\%20PADA\%20ANAK\%20USIA\%2 03\%20SAMPAI\%206\%20BULAN.pdf Diakses 9 Mei 2018

Roesli U. 2005. Mengenal ASI Eksklusif. Jakarta:Trubus Agriwidya, pp:3-35.

Sari, Hanika N. 2011. Hubungan Pemberian ASI Eksklusif Dengan

Perkembangan Motorik Anak Usia 6-8 Bulan di Wilayah Kerja Puskesmas Dersalam Kabupaten Kudus.http://www.thedigilib.com/doc/237413-hubungan-pemberian-asieksklusif-dengan-perkembangan-motorik-anak-usia-6-8-bulan2011\#.Ugm2gWXIHIU (Diakses 2 Agustus 2018)

Saryono. 2010. Kumpulan Instrumen Penelitian Kesehatan. Yogyakarta : Mulia Medika.

Siregar, A. 2004. Pemberian ASI eksklusif dan faktor yang mempengaruhinya. http://library.usu.ac.id/download/fkm/fkm-arifin.pdf Diakses 5 Juni 2018.

Soekirman. 2000. Ilmu Gizi dan Aplikasinya untuk Keluarga dan Masyarakat.Departemen Pendidikan. Jakarta.

Soetjiningsih. 2006. ASI Petunjuk Untuk Tenaga kerja Kesehatan. EGC. Jakarta.

Stang. 2005. Biostatistik. Makassar : FKM Unhas.

Sudarianto. 2010. Profit Kesehatan Sulawesi Selatan 2010. Makassar

http://www.dinkes-sulsel.go.id Diakses Mei 2018.

Suharjo. 2002. Berbagai Cara Pendidikan Gizi. Penerbit Bumi Aksara : Jakarta.

Suyatno. 2010. Pemberian ASI Secara Eksklusif Dan Pertumbuhan Bayi Usia 0-3 Bulan. Studi Kasus Pada Bayi Yang Dilahirkan DI 4 Rumah Sakit Bersalin Di Kota Semarang.http://www.scribd.com/doc/74366192/Pemberian-Asi-Secra-EksklusifDan-Pertumbuhan-Bayi (Diakses 2 agustus 2018).

Supariasa, Nyoman, I Dewa, dkk, 2002. Penilaian Status Gizi. Penerbit EGC. Kedokteran : Jakarta 